Jurnal Pemberdayaan: Publikasi Hasil Pengabdian kepada Masyarakat

Vol. 2, No. 3, Desember 2018, Hal. 431-440

ISSN: 2580-2569; e-ISSN: XXXX-XXXX

DOI:

\title{
PELATIHAN PENINGKATAN KESEHATAN LINGKUNGAN PADA KADER 'AISYIAH BANGUNTAPAN UTARA
}

\author{
Ahmad Faizal Rangkuti ${ }^{1}$, Musfirah, Helfi Agustin ${ }^{2}$ \\ Universitas Ahmad Dahlan, Jl. Prof. Dr. Soepomo Sh, Warungboto, Umbulharjo, Yogyakarta 551641,2 \\ Email: musfirah@ikm.uad.ac.id
}

\begin{abstract}
ABSTRAK
Pengelolaan sampah yang dilaksanakan sejak dari rumah tangga merupakan upaya memandirikan masyarakat dalam menyelesaikan permasalahan kesehatan lingkungan.Permasalahan sampah tidak hanya menjadi tanggung jawab pemerintah, akan tetapi menjadi tanggung jawab seluruh lapisan masyarakat. Banguntapan merupakan daerah yang sangat potensial untuk pemberdayaan masyarakat yang didukung oleh Sumber Daya Manusia khususnya Ibu kader 'Aisyiah PCA Banguntapan Utara.Lokasi pengabdian tersebar dalam 3 PRA yaitu PRA Banguntapan 4, PRA Baturetno 1 dan PRA Baturetno 2 yang dilaksanakan pada bulan Februari - Maret 2018. Metode yang digunakan dalam pemberdayaan masyarakat adalah penyuluhan dan praktek.Upaya peningkatan sanitasi lingkungan terhadap kader 'Aisyiah di lokasi ini dilakukan melalui 3 pelatihan yaitu pengolahan sampah organik metoda komposting (PRA Baturetno 1),pengolahan sampah plastik menjadi dompet (PRA Banguntapan 4) dan pemanfaatan sampah botol plastik minuman sebagai media hidroponik (PRA Baturetno 2).Hasilnya menunjukkan kehadiran peserta selama kegiatan 90\%.Penilaian capaian peningkatan kemampuan dalam mengolah sampah lingkungan rumah tangga menunjukkan hasil yang signifikan. Peserta terampil menangani limbah ternak dengan mengolah sampah menjadi 3 (tiga) produk yaitu media hidroponik dari botol plastik,kompos dan dompet unik dari plastik sashet kopi.Kesimpulannya, secara umum berjalan dengan sukses dan baik terbukti dari hasil penilaian oleh peserta berada pada kategori "Sangat Baik".Peserta memberikan apresiasi dan sambutan yang positif dengan adanya kegiatan ini.
\end{abstract}

Kata kunci: Pemberdayaan, Sanitasi Lingkungan, Kesehatan Masyarakat

\begin{abstract}
Waste management carried out from the household is an effort to empower the community in solving environmental health problems. Waste problems are not only the responsibility of the government, but are the responsibility of all levels of society. Banguntapan is a very potential area for community empowerment supported by Human Resources, especially the cadre of Aisyiah PCA Banguntapan Utara. The location of service is spread in 3 PRAs namely PRA Banguntapan 4, PRA Baturetno 1 and PRA Baturetno 2 which are held from February to March 2018 the method used in community empowerment is counseling and practice. Efforts to improve environmental sanitation of Aisyiah cadres at this location were carried out through 3 training, namely processing organic composting methods (PRA Baturetno 1), processing plastic waste into wallets (PRA Banguntapan 4) and the use of beverage plastic bottle waste as a hydroponic media (Baturetno PRA 2). The results show the presence of participants during the activity of $90 \%$. Assessment of the achievement of increased capacity in processing household waste environment shows significant results. Participants were skilled at handling livestock waste by processing waste into 3 (three) products, namely hydroponic media from plastic bottles, compost and unique wallets from coffee sachet plastic. In conclusion, generally running successfully and well proven is from the results of the assessment by participants in the category "Very Good ". Participants gave positive appreciation and welcome with this activity.
\end{abstract}

Keywords: Empowerment, Environmental Sanitation, Public Health 


\section{PENDAHULUAN}

Sampah merupakan suatu barang yang dihasilkan dari aktivitas manusia dan makhluk hidup lainnya yang tidak digunakan lagi. Sampah akan menjadi persoalan lingkungan jika tidak dikelola dengan baik. Semakin menigkatnya volume sampah dari tahun ke tahun ini maka menjadi alasan yang kuat bahwa masalah sampah merupakan masalah utama yang harus dipecahkan baik dalam jangka pendek, menengah maupun jangka panjang. Berbagai upaya pemerintah untuk menangani sampah telah dilakukan antara lain adanya anggaran untuk biaya operasional dan sarana prasarana pengelolaan sampah. Anggaran tersebut dialokasikan untuk pengelolaan Tempat Pembuangan Akhir (TPA) sampah dan infrastruktur untuk mengelola sampah. Akan tetapi permasalahan sampah masih menjadi masalah yang cukup serius untuk ditangani. Hal ini karena TPA mempunyai keterbatasan penampungan. Saat ini hampir seluruh sampah berakhir di TPA sehingga beban TPA menjadi sangat berat, diperlukan lahan yang cukup luas dan diperlukan fasilitas perlindungan lingkungan yang relatif mahal. Oleh sebab itu meminimalisir jumlah sampah dari tingkat rumah tangga dianggap merupakan solusi yang tepat untuk menangani masalah sampah rumah tangga (Notoatmodjo, 2007).

Secara lokal, limbah padat yang tidak ditangani dengan baik berkontribusi terhadap estetika lingkungan, pencemaran udara, dan dampak kesehatan masyarakat seperti penyakit pernafasan, diare, dan demam berdarah (World Bank, 2012). Beberapa indikator sanitasi lingkungan yang direkomendasikan oleh Departemen Kesehatan Republik Indonesia antara lain persentase jumlah rumah sehat mencapai $80 \%$. Masalah kesehatan lingkungan misalnya perumahan, pembuangan feses manusia dan kotoran ternak, penyediaan air bersih, pembuangan sampah, dan pembuangan air limbah, berpengaruh terhadap kesehatan masyarakat terutama pada masalah kesehatan lingkungan rumah tangga. Secara keseluruhan kondisi kesehatan lingkungan di Indonesia masih sangat memprihatinkan (Soemirat, 2011).

Pengelolaan dan pengolahan sampah yang dilaksanakan sejak dari rumah tangga merupakan upaya untuk memandirikan masyarakat dalam menyelesaikan permasalahan kesehatannya lingkungan. Oleh sebab itu melalui upaya pemberdayaan masyarakat dalam menyelesaikan permasalahan sampah, diharapkan masalah sampah tidak hanya menjadi tanggung jawab pemerintah, akan tetapi menjadi tanggung jawab seluruh lapisan masyarakat. Mengelola sampah di tingkat rumah tangga dilakukan dengan prinsip reduce, reuse dan recycle atau pengurangan, penggunaan kembali dan daur ulang sampah. 
Berdasarkan hasil diskusi singkat dengan pimpinan cabang Aisyiyah dan sekretarisnya di Baturetno 2, masyarakat belum memiliki sistem pemilahan sampah dan di beberapa wilayah Banguntapan Utara lainnya masih mengandalkan pengangkutan sampah rumah tangga oleh petugas kebersihan. Pada umumnya sampah rumah tangga dibuang tanpa melakukan pemilahan sampah terlebih dahulu. Sampah -sampah rumah tangga diangkat oleh petugas kebersihan di tingkat RT untuk diangkut ke Tempat Pembuangan Sampah Sementara (TPS) yang selanjutnya akan diangkut oleh truk sampah ke tempat pembuangan akhir. Sementara beberapa masyarakat lainnya membakar sampah di halaman, terutama sampah yang berasal dari dedaunan di halaman rumah. Atas kesepakatan bersama yang dilaksanakan pada saat rapat anggota PCA yang terdiri dari ibu-ibu dari enam ranting Aisyiyah yang ada di Cabang Banguntapan, maka disepakatilah untuk mengadakan pelatihan mengolah sampah rumah tangga di tiga ranting yakni ranting Baturetno 1 Baturetno 2 dan Banguntapan 4.

\section{METODE PELAKSANAAN}

Mencantumkan metode atau teknik yang digunakan, alat- alat khusus yang diperlukan dalam pengabdian, dan cara analisis data secara jelas. Metode terdiri dari 2 sub bab yaitu

1. Alat dan bahan

- Media tanam hidroponik

a. Botol air mineral ukuran $600 \mathrm{ml}$

b. Rockwool (salah satu media tanam untuk hidroponik, bisa dibeli di toko pertanian/penjual bibit/benih. Rockwool dapat diganti dengan gulungan kapas, busa bekas jok kursi.

c. Kain Flannel/sumbu kompor sebagai sumbu untuk mengalirkan air ke bibit di atas botol.

d. Bibit tanaman

e. $A B-$ Mix Nutrisi tanaman Hidroponik

- Pengolahan Sampah Organik Menjadi Kompos Metode Takakura
a. Starter dengan larutan gula
b. Starter dengan larutan garam.
c. Tanah
d. Sekam/dedak
e. Keranjang kompos takakura
f. Sampah organik 
- Pembuatan Dompet Plastik dari Plastik Pembungkus Kopi
a. Bungkus kopi (-/+ 100 sachet)
b. Gunting
c. Ritsleting
d. Jarum dan benang jahit

2. Jalannya pengabdian.

Kegiatan pengabdian masyarakat dilaksanakan dalam beberapa aktivitasi, diantaranya dapat dilihat pada Tabel 1 .

Tabel 1. Metode, Kegiatan, JKP dan keterlibatan mahasiswa

\begin{tabular}{|c|c|c|c|c|}
\hline No & Metode & Kegiatan & JKP & $\begin{array}{c}\text { Keterlibatan } \\
\text { Mahasiswa }\end{array}$ \\
\hline \multirow[t]{4}{*}{1} & \multirow[t]{4}{*}{$\begin{array}{l}\text { Pendidikan } \\
\text { masyarakat }\end{array}$} & 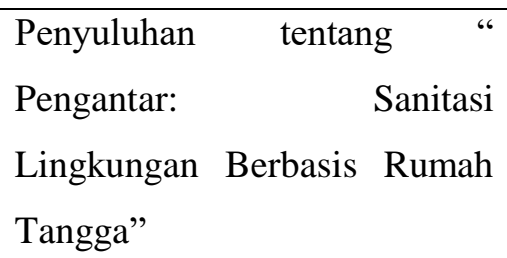 & $1 \times 1 \mathrm{jam}$ & 1 Orang \\
\hline & & $\begin{array}{l}\text { Penyuluhan tentang "Penataan } \\
\text { Kampung Sehat Menuju } \\
\text { Kabupaten Bantul Sehat } \\
\text { Melalui Gerakan 3R" }\end{array}$ & $1 \times 1,5$ jam & 1 Orang \\
\hline & & $\begin{array}{l}\text { Penyuluhan dan praktek } \\
\text { "Pengelolaan Limbah Organik } \\
\text { Rumah Tangga Menuju } \\
\text { Kabupaten Bantul Sehat" }\end{array}$ & $1 \times 1,5$ jam & 1 Orang \\
\hline & & $\begin{array}{lr}\text { Penyuluhan } & \text { tentang } \\
\text { "Pengolahan } & \text { Limbah } \\
\text { Anorganik Bahan Plastik } \\
\text { Menjadi Produk Kerajinan } \\
\text { Kreatif Dalam Mewujudkan } \\
\text { Kesehatan Lingkungan } \\
\text { Tatanan Rumah Tangga" }\end{array}$ & $1 \times 1,5 \mathrm{jam}$ & 1 Orang \\
\hline \multirow[t]{2}{*}{2} & \multirow[t]{2}{*}{ Praktek } & $\begin{array}{lcr}\text { Mengolah } & \text { Botol } & \text { Bekas } \\
\text { Menjadi } & \text { Media } & \text { Tanam } \\
\text { Hidroponik metoda Wicks }\end{array}$ & 1 x 45 Menit & 1 Orang \\
\hline & & $\begin{array}{l}\text { Mengolah Sampah Rumah } \\
\text { Tangga Menjadi Kompos }\end{array}$ & $1 \times 1.25 \mathrm{jam}$ & 1 Orang \\
\hline
\end{tabular}




\begin{tabular}{|l|l|l|l|}
\hline & $\begin{array}{l}\text { Mengolah Plastik Bekas (Saset } \\
\text { Kopi) Menjadi Dompet Unik } \\
\text { Cantik }\end{array}$ & 1.25 jam \\
\hline
\end{tabular}

\section{HASIL, PEMBAHASAN DAN DAMPAK \\ Profil Desa}

Kecamatan Banguntapan merupakan salah satu kecamatan yang berada di di daerah Kabupaten Bantul dengan luas wilayah 2.848 Ha. Kondisi geografisnya sangat mendukung untuk pengembangan daerah pertanian, perkebunan dan juga peternakan. Sebagaimana sistem pembagian ranting di bawah organisasi Aisyiah yaitu terdapat PRA Banguntapan 1 - 4, dan PRA Baturetno 12. Mayoritas masyrakat bermata pencaharian sebagai petani,peternak dan buruh.

\section{Gambaran Pelaksanaan}

Program pengabdian kepada masyarakat (PPM) reguler ini di laksanakan pada tanggal 17 Februari hingga 6 April 2018. Tim pelaksana terdiri atas Ahmad Faizal Rangkuti, M.Kes., Musfirah, M.Kes., dan Helfi Agustin, M.KM. serta melibatkan mitra Pimpinan Cabang Aisyiyah (PCA) Banguntapan Utara.

Pelaksanaan pelatihan di tingkat komunitas berkoordinasi dengan Pimpinan Cabang Aisyiyah Kecamatan Banguntapan Utara, yang kemudian menunjuk 3 PRA yakni PRA Banguntapan 4, PRA Baturetno 1 dan PRA Baturetno 2 sebagai lokasi pengabdian. Koordinasi dilakukan sejak Februari - Maret mengenai perizinan dan rekomendasi pelatihan dri pimpinan cabang dan pimpinan ranting. Selanjutnya sesuai dengan rencana kegiatan, pada hari Senin tanggal 5 Februari 2018 dilakukan koordinasi mengenai hari pelaksanaan dan persiapan lain-lain pada saat rapat PCA Banguntapan Utara. Akhirnya disepakati pelatihan I diadakan pada akhir 27 Februari 2018 di Baturetno 1, pelatihan kedua 6 Maret 2018 di Banguntapan 4 dan pada 17 Maret 2018 di Banguntapan 4. Pendekatan kepada kelompok masyarakat RT 02 difasilitasi oleh ketua dan sekretaris PRA Banguntapan 4.

Tim PPM membuat komitmen dengan tiga PRA untuk melaksanakan program pengolahan sampah di tiga ranting tersebut. Pengolahan sampah organik dilaksanakan di ranting Aisyiyah Baturetno 1 dengan pelatihan komposting, pengolahan sampah plastik dilaksanakan di ranting Banguntapan 4 dengan pelatihan pembuatan dompet dengan memanfaatkan kemasan plastik dan pelatihan memanfaatkan sampah botol plastik minuman kemasan sebai media hidroponik bersama dengan ibu - ibu kelompok dasawisma di RT 02 Rojogeten Baturetno 2. 
Realisasi komitmen dalam kegiatan gotong royong menyiram tanaman yang dilaksanakan secara rutin setiap Kamis sore dengan ibu-ibu RT 02.Persiapan yang diakukan untuk penyelenggaraan pelatihan dilakukan secara bersama-sama oleh setiap anggota tim. Uraian tugas dibagi sehingga setiap orang dalam tim mempunyai tanggung jawab pekerjaan, misalnya Faizal Rangkuti bertugas memberikan pelatihan tentang pembuatan kompos dari sampah yang dihasilkan dari rumah tangga dan mengkomunikasikan dan menghubungkan informasi dengan berbagai pihak yan terlibat melalui telepon seluler sehingga informasi hanya masuk dan keluar satu pintu, dengan demikian dapat mengurangi kesalahan komunikasi. Musfirah bertanggung jawab terhadap pelatihan pengolahan sampah non organik dari plastik bungkus minuman instant, sedangkan Helfi Agustin bertugas memberikan pelatihan tentang penggunaan kembali sampah botol plastik untuk dimanfaatkan sebagai media tanam hidroponik dan melatih masyarakat RT 02 untuk bertanam secara hidroponik. Tim dibantu oleh mahasiswa yang bertugas sebagai tenaga teknis selama pelaksanaan kegiatan seperti membeli bahan, mengangkat-angkut bahan pelatihan dan lain-lain.

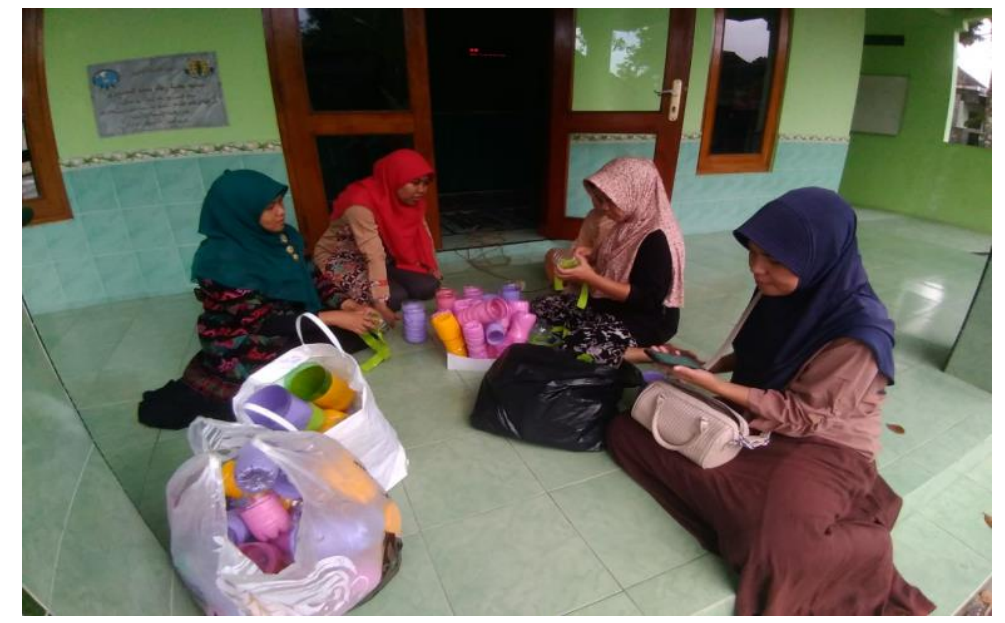

Gambar 1. Peserta praktek pemanfaatan botol plastik sebagai media hidroponik

Setiap peserta sangat antusias dalam mengikuti setiap langkah-langkah pelatihan pemanfaatan botol plastik. Banyak hal yang mereka tanyakan seputar media hidroponik tersebut, seperti botol apa saja yang bisa dimanfaatkan untuk medianya. Semua jenis botol minuman plastik sebenarnya bisa digunakan untuk media hidroponik, hanya disesuaikan dengan kebutuhan. Sayuran yang bisa ditanam di media tersebut kebanyakan dari jenis sayuran. 


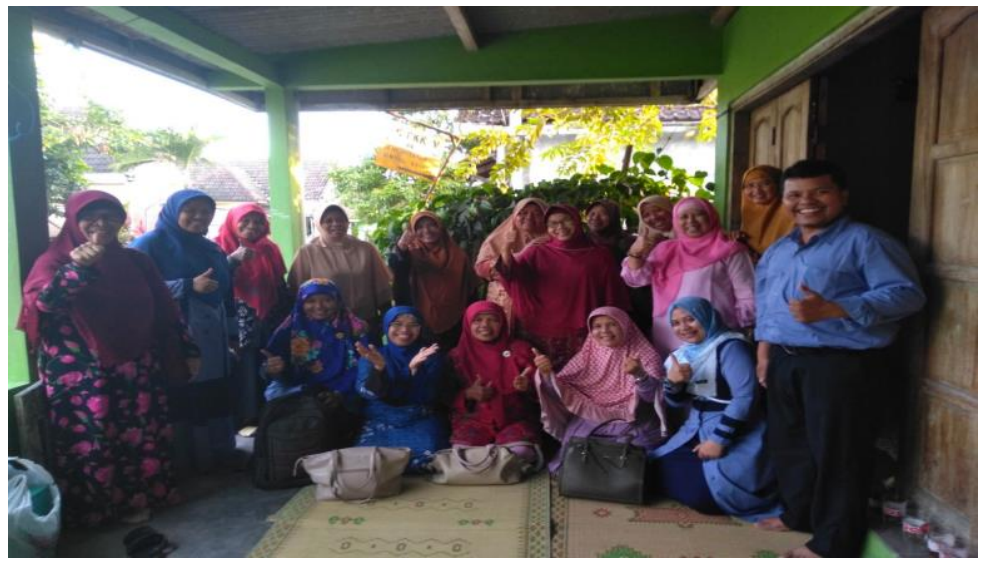

Gambar 2. Peserta pelatihan pengolahan limbah organik rumah tangga

Pelatihan ini bertujuan mengenalkan kepada anggota PRA dan Masyarakat lainnya tentang metode pemanfaatan limbah organik yang sederhana untuk tingkat rumah tangga. Peserta pelatihan sangat tertarik uantuk praktek di rumah. Sebagai bentuk tindak lanjut dari kegiatan, Tim PPM memberikan tugas kepada peserta untuk praktek di rumah. Seminggu kemudian tim melakukan evaluasi terhadap peserta, dari peserta ada yang berhasil, tidak berhasil dan tentu juga ada yang tidak praktek sama sekali. Secara umum mereka sangat senang dengan kegiatan yang telah dilaksankan dan berharap akan ada lagi kegiatan yang sama di waktu lainnya.

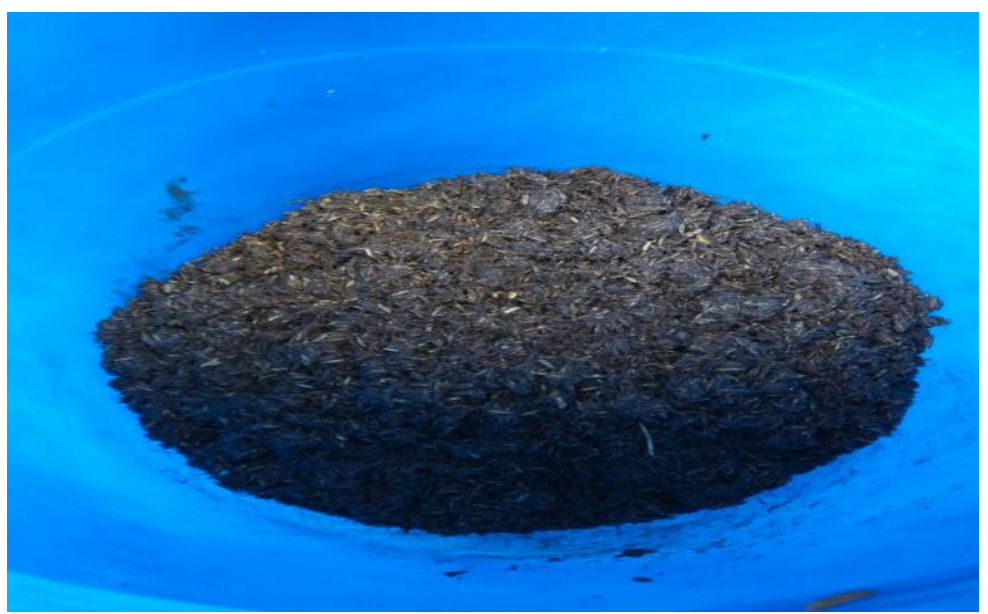

Gambar 3. Kompos Hasil Praktek Peserta

Peserta di PRA banguntapan 4 tidak kalah semangat dengan PRA yang lainnya. Mereka mendapatkan pengetahuan yang banyak terkait bagaimana mengelola bekas bungkus makanan dan bubuk kopi menjadi barang yang bermanfaat. Hasil penyuluhan dan pelatihannya menunjukkan bahwa limbah tersebut masih bisa di olah menjadi dompet unik.

Pelatihan yang dilaksanakan selama dua hari ini memberikan kesan yang cukup baik bagi PRA nya karena menjadi kegiatan tambahan bagi mereka nantinya yang dapat menghasilkan uang dari hanya mengelola sampah. 


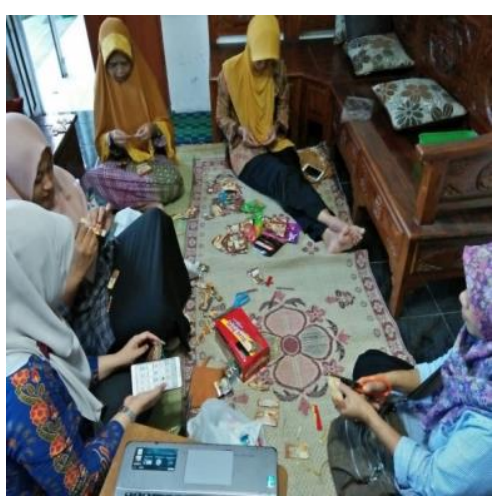

Gambar 4. Praktek membuat dompet unik dari bekas bungks kopi

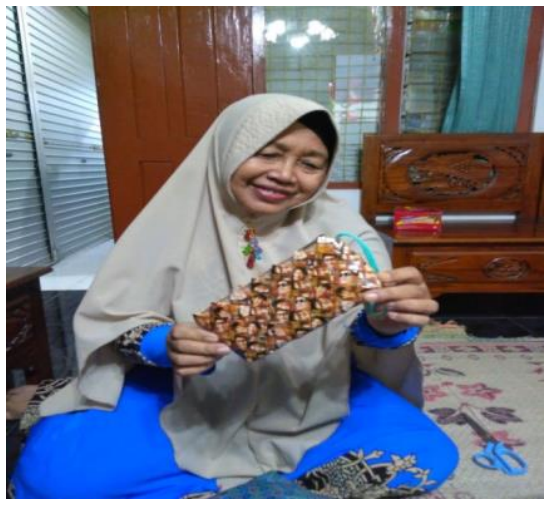

Gambar 5. Peserta dengan dompet unik dari bungkus kopi

Total koordinasi dengan PCA dilaksanakan 2 kali, koordinasi dengan seluruh anggota PCA yang terdiri dari PRA - PRA se Banguntapan Utara dilaksanakan 1 kali, pelaksanaan pelatihan direalisasikan 3 kali dan montoring dan evaluasi masing-masing pelatihan dilaksanakan 2 kali. Seluruh peserta antusias mengikuti sesi demi sesi pelatihan ini. Sebagai bahan penunjang peningkatan pengetahuan dan keterampilan peserta pelatihan, diberikan modul berjudul "Mendulag Uang dengan Daur Ulang” kepada peserta pelatihan.

\section{Evaluasi Proses dan Dampak}

Evaluasi proses dilakukan dengan tujuan untuk menilai proses selama kegiatan berlangsung. Dilakukan dengan cara memberikan kuesioner kepada para peserta pelatihan. Indikator penilaian evaluasi proses meliputi penilaian tentang tema pelatihan, ketepatan waktu, suasana, sikap panitia. Evaluasi Pelaksanaan PPM berdasarkan Tabel 3 menunjukkan bahwa nilai rata-rata hasil penilaian dalam kategori tertinggi yaitu "sangat baik" sebesar $71,40 \%$.

Tabel 2. Evaluasi Pelaksanaan PPM Reguler Gasal 2017/2018

\begin{tabular}{|r|l|c|c|}
\hline \multirow{2}{*}{ No } & \multicolumn{2}{|c|}{ Indikator Penilaian } & \multicolumn{2}{c|}{ Hasil Penilaian } \\
\cline { 3 - 4 } & & Cukup & Sangat Baik \\
\hline 1 & Tema Pelatihan & $35 \%$ & $65 \%$ \\
\hline 2 & Ketepatan Waktu & $25 \%$ & $75 \%$ \\
\hline 3 & Suasana & $15 \%$ & $85 \%$ \\
\hline 4 & Sikap Panitia & $25 \%$ & $75 \%$ \\
\hline & Total & $\mathbf{1 0 0 \%}$ & $\mathbf{3 0 0 \%}$ \\
\hline & Rata2 & $\mathbf{2 5 \%}$ & $\mathbf{7 5 \%}$ \\
\hline
\end{tabular}

Data primer, 2018 
Dengan demikian, dapat disimpulkan bahwa peserta menyambut positif dan antusias dalam mengikuti pelatihan tersebut agar menjadi kader 'Aisyiah yang terampil dalam menangani limbah rumah tangga. Kegiatan ini menurut kader 'Aisyiah mampu meminimalisir dampak kesehatan lingkungan serta bisa dijadikan wadah untuk pengembangan diri dan mengedukasi warga lainnya agar bisa mengolah limbah padat rumah tangga baik organik maupun anorganik menjadi barang bernilai ekonomis seperti dompet plastik, pupuk kompos, dan media hidroponik tanpa mengabaikan aspek kesehatan lingkungan.

\section{SIMPULAN}

Berdasarkan hasil dan dampak kegiatan diatas, maka simpulan dari kegiatan ini adalah sebagai berikut:

1. Peserta pelatihan sangat antusias dalam mengikuti kegiatan pelatihan ini. Dibuktikan dengan kehadiran peserta selama kegiatan $90 \%$.

2. Peserta pelatihan terampil menangani limbah ternak dengan cara mengolah limbah ternak menjadi 3 (tiga) produk yaitu media hidroponik dari botol plastik, pupuk kompos dan dompet unik dari plastik sashet kopi.

3. Hasil evaluasi proses pelaksanaan kegiatan PPM regular, secara umum berjalan dengan sukses dan baik terbukti dari hasil penilaian oleh peserta berada pada kategori "Sangat Baik”. Peserta memberikan apresiasi dan sambutan yang

\section{DAFTAR PUSTAKA}

Notoatmodjo, S. (2007). Kesehatan Masyarakat; Ilmu dan Seni. Jakarta: Rineka Cipta.

World Bank. (2012). What a Waste: A Global Review of Solid Waste Management. Washington, DC.

Soemirat, J. (2011). Kesehatan Lingkungan, Edisi Revisi. Yogyakarta: Gadjah Mada University Press. 
